\title{
Strategic positioning of the Russian Far East gold mining industry
}

\author{
Aleksei Sobolev ${ }^{1 *}$, Peter Gibson ${ }^{2}$, Gennadei Sekisov ${ }^{1}$ and Anton Andriushenko ${ }^{1}$ \\ ${ }^{1}$ Mining Institute FEB RAS, 680000, 51 Turgenev st., Khabarovsk, Russia \\ ${ }^{2}$ School of Mechanical, Materials and Mechatronics, University of Wollongong, Northfields Ave, \\ Wollongong NSW 2522, Australia.
}

\begin{abstract}
The objectives of this paper is to investigate internal and external factors influencing the gold mining in Russian Far East. Justification of the methodological and practical recommendations as well as effective strategies which in full measure correspond to the range of economic and technical factors aimed to increase the effectiveness of gold mining industry in Russia are presented. In this paper, we analysed the current state and main development trends, identified strengths and weaknesses of the internal environment, as well as opportunities and threats of the external environment for the gold mining enterprises based on SWOT analysis. Based on the analysis identified directions of production strategies improvements, sound strategic response and strategic management mechanisms to mitigate the challenges of current times. Their implementation will allow companies using the strengths to reduce the negative impact of weaknesses and prevent key threats, that will significantly increase the competitiveness and economic efficiency of the Russian gold mining industry.
\end{abstract}

Keywords: SWOT analysis, management strategies, Russian Far-East, mining companies.

\section{Introduction}

Economic and social development of Russia and its Eastern territory is associated with effective development of mineral resources, especially gold-ore. For many decades, preferably placer deposits of gold were explored. However, from the beginning of the 20th century, in connection with the exhaustion of placer resources, mining companies were rearranged and began intensive exploration and development of gold-ore deposits. Since 2002, production of gold from ore deposits exceeded production from the placers, and this tendency lasts for the last fifteen years, and currently the share accounted as $70 \%$ on average of the extracted precious metal (Fig. 1). This is, mainly, a result of implementation of new projects, expansion and modernization of existing facilities for gold ore mining.

\footnotetext{
*Corresponding author: alexsoboll@mail.ru
} 


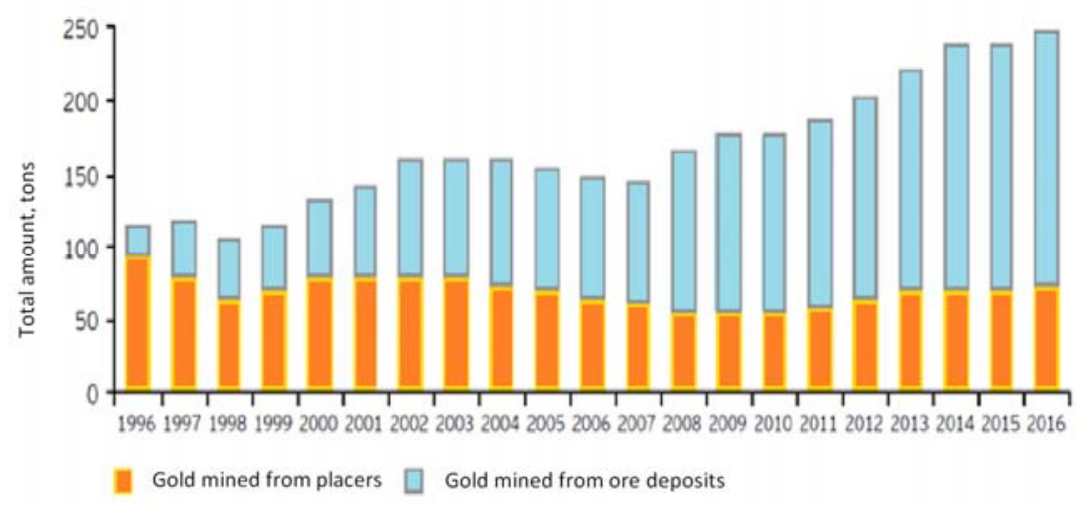

Fig. 1. Dynamics of annual production of gold in Russia from ore and placer deposits [1]

So successful performance in exploitation of ore deposits has allowed Russia introduce constantly growing rate of gold mining and reach at 2013 and keep it through the next years, the third place in the list of world's gold producing leading countries (Fig. 2).

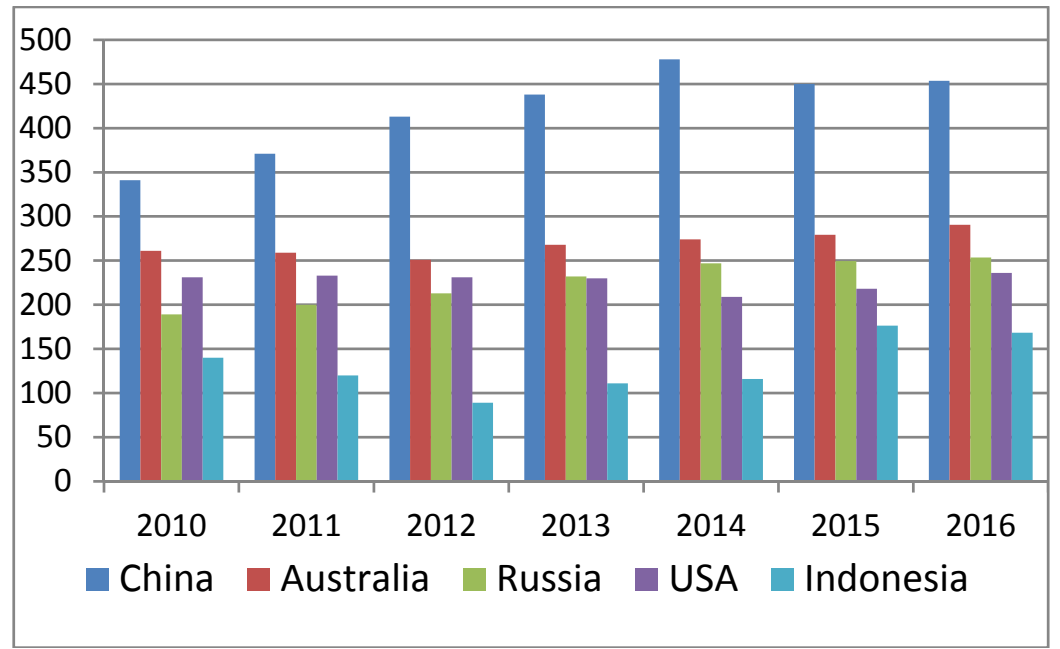

Fig. 2. Dynamics of annual production of gold in TOP-5 of the largest world's gold producing countries [2]

The Far Eastern region of Russia is one of the leading gold mining province and has significant resources of gold ore, part of which is being developed successfully. Previously, the main role was played by large and medium-scale gold deposits. However, because of the years of intensive exploitation, the resource potential of such deposits has significantly decreased. Consequently, large scale and rich mines are becoming less common. In this regard, the development of small-scale gold-ore deposits is attracting more attention. These are located all-around its territory and concentrated in almost all gold-mining regions and provinces. Currently, due to it wide spreading, prospecting and mining gold from small scale deposits is a very important issue for local government and enterprises however over the past few decades in development was involved in only about 20 of small scale deposits.

Significant part of gold ore reserves from these deposits is concentrated in steeply dipping veins and vein-shaped bodies characterized by a complex structure and the presence of several types of ores (Fig.3). This is associated with high ore dilution and stripping ratios, 
which determine relatively high operating costs when using traditional technical equipment and technological methods for their mining. This is partially why, there have been significant obstacles to build new gold mines on small scale gold deposits, with a number of notable failures. Also, the increasingly poor economic quality of the available resource base, a lack of highly effective technologies and reliable, flexible strategies for the successful development of small-scale gold deposits contributed to failures.

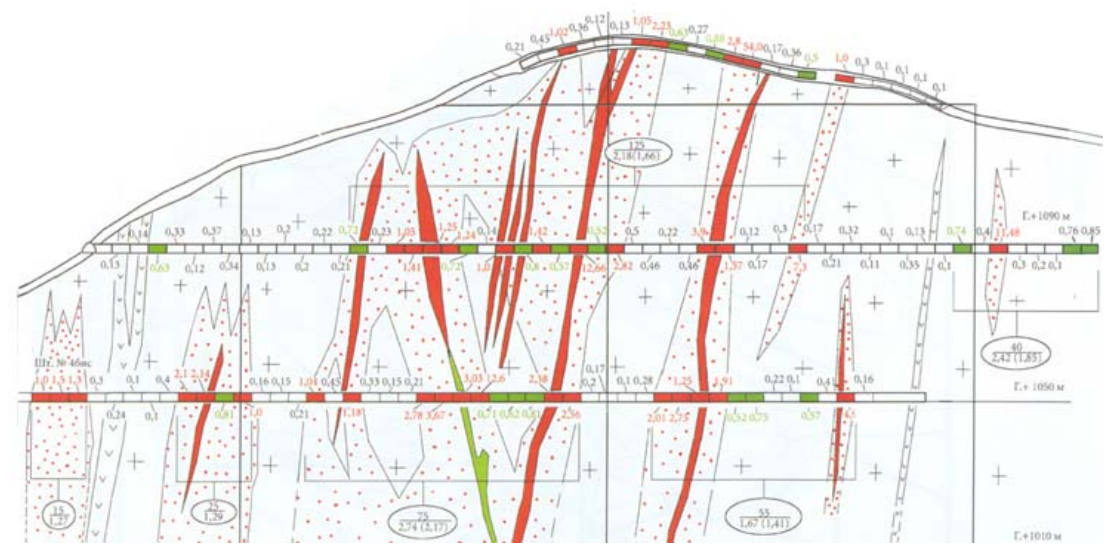

Fig. 3. Geological section of typical small-scale gold deposit

That is why the successful management strategies for each of the stage of resource development: prospecting, mining, conservation, liquidation of mining facilities, will lead to the success of the projects in an ever changing environment and have important economic significance.

\section{The main internal and external factors of SWOT analysis}

The subject of the SWOT analysis is a comprehensive review of external and internal strategic factors that influence the formation of production strategies of gold miners. The purpose of this SWOT analysis is to investigate the extent to which internal and external factors influence the efficiency and sustainability of gold mining companies and, on this basis, to develop the basic strategic options, taking into account different combinations of strategic factors. On the assessments basis of the strengths and weaknesses of gold mining enterprises, as well as opportunities and threats from the environment, the SWOT-analysis was adapted in this research to estimate the current state of gold mining industry in Russia. The results obtained (structure of external and internal environment factors) can be used in managing gold mining companies and as a tool to shape strategic options and alternatives aimed to efficient economic development.

\section{Strengths:}

Volume of the mineral resources base and license prices. Russia has a massive gold resource base - ranked second in the world's reserves and resources of gold [2]; the average content of gold in the remaining probable and proved reserves exceeds that of most other gold-producing countries $[3,4]$. The low prices of geological exploration licenses give a significant potential of new projects for resource exploration and very low competition for obtaining new leases.

The devaluation of the ruble. Based on information provided by the Union of Gold Producers of Russia, due to the devaluation of the ruble, the average cost of gold production 
decreased in 2015 for 6-10 leading gold mining enterprises by 25-30\% compared to 2014, (from $\$ 900-1100$ /oz. to $\$ 750$ - 950 /oz. respectively).

Figure 4 shows the dynamics of the weakening of the ruble against foreign currencies in the period from 2008 to 2020 . Thus, the growth rate of the US dollar against Russian rubble for 7.5 years was $208 \%$, Euro — $272 \%$ respectively. [5]

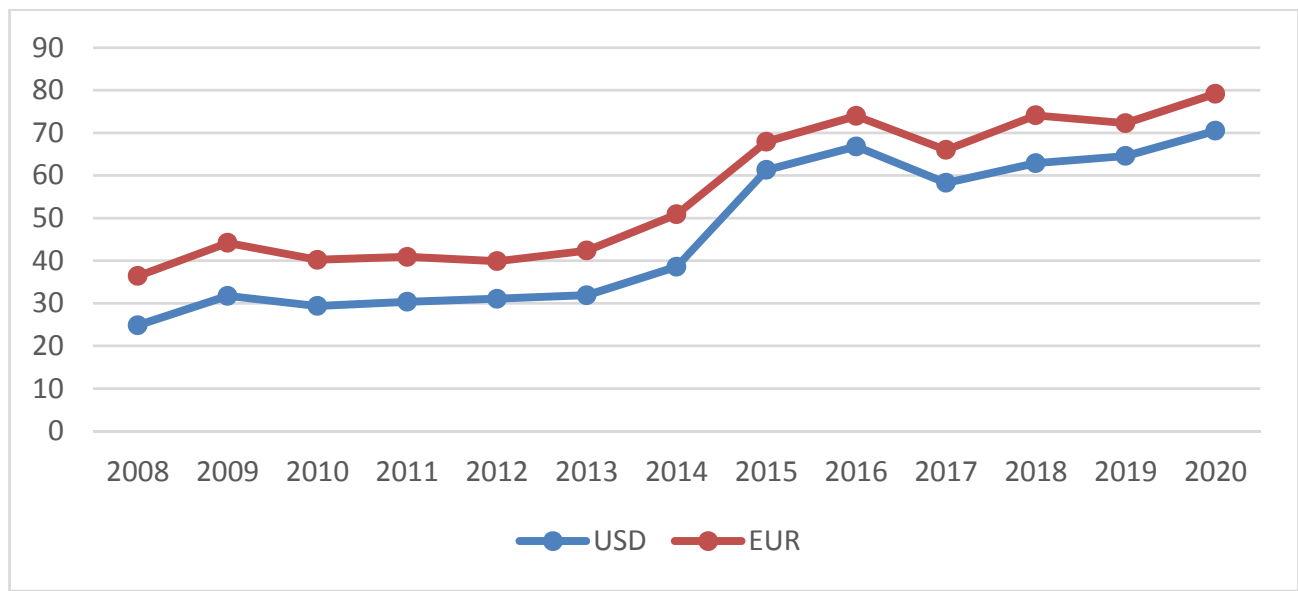

Fig.4 - Dynamics of the annual average exchange rate of foreign currencies to Russian ruble.

Political aspects, Taxes and Liquidity of gold. From a political perspective, the Russian government has become more open to international investors. Russia has created new initiatives to attract funding for the early stages of exploration and mining. [6] However, strict control of the gold mining by authorities will continue under current system of regulation but possibly some of administrative barriers will be gradually eliminated. The taxes in Russia are comparable with the global average taxes on gold production, including tax on mineral extraction, which is $6 \%$. The Central Bank of Russia continues to buy gold on a large scale, providing domestic liquidity of gold. Furthermore, there are no limitations on the gold turnover for producers. Since 1998, Russian banks have been allowed to export gold abroad and, since 2002, gold mining companies also have the right to do so.

\section{Weaknesses:}

Lack of necessary infrastructure due to significant remoteness, the inaccessibility of the territory and the complexity of transportation system the costs of mining in the North-East of Russia, where the main gold reserves are being concentrated and the gold mining sites are located, is 2-10 times higher [7] than in other geographical regions. The trucks access to this territory is only practically feasible during the winter times, from beginning of December till the end of March when the ground is solid and the rivers and swamps are frozen. Every year mining company have to invest millions of dollars into the winter road infrastructure, to organize the supply chain, build and support hundreds kilometers of the winter roads which will disappear after each spring. During the summer and in between the seasons the access to the mining sites is possible only by the airplane or helicopter, that make the bulk fuel, food, equipment or chemical reagent supply economically unfeasible, as a result total cost of cargo delivery to the mining sites is 5-10 times higher, cost of electricity 4-8 times, all of this makes all the types of equipment manufactured on the spot, as well as shipped 2-4 times higher in [8]. Harsh climate conditions and low population makes wages expenses in the North-East 2,5-3 times higher than in the Central or Western part of the country. The investment attractiveness of the industry, is reduced by the constant growth in the price of fuel and 
energy, though the price of 1 litter of diesel fuel in Russia increased up to $30 \%$ for the last 4 years.

\section{Opportunities:}

Sanctions against Russia have restricted the access of Russian banks and companies (including gold miners) to international capital markets [9], as a result investment in gold mining by Russian banks and companies has reduced because of the problems with cash flow [10]. Because of this, difficulties with the introduction of new capacity and technology and equipment modernization is being predicted, as well as reduction of supplies of high-tech equipment, in the number of laboratory analytical centers etc., that creates a positive climate as opportunity for the international investors arises.

However, this opportunity is at the same time a threat, since possible sudden lifting of sanctions due to the warming political relationships with Western countries and the inflow into the industry of new capital will significantly increase competition in the gold mining sector that will lead to the struggle for the gold ore leases.

\section{Threats:}

Non-confirmation of reserves, decrease in head grades of the ore is the main threats in gold mining [11]. Random fluctuations in the gold content in samples (both individual and group) are quite typical, they are mainly related to the fact that gold in the ore is represented by separate particles of various sizes and their clusters. using current methods of exploration and testing often leads to non-confirmation of reserves [12,13].

\section{Results and discussion}

Analysis of resource base shows that the small scale gold deposits are more common in Russian gold mining regions and some of previously explored small-scale gold deposits, located relatively close to each other, can be a major part of the mineral resource base for mining companies. Based on the geological, geographical and economical conditions, it seems appropriate that several (5-7) small gold deposits in a single mining district might be exploited. An independently created mining hub is the solution for the long company's lifespan, which will be achieved by subsequent involvement into development small gold deposits of the mining area, that will allow to use one processing plant and share all facilities as well as employees.

In spite of the arrival in the country of the foreign consulting companies, certified laboratories, engineering structures and modern computer technologies for exploration and mining this unfortunately did not significantly increase the level of use of technologies and equipment in medium and small companies, since they are too costly and usually not affordable. This weakness, the use of low level technologies as well as out-of-date equipment in the production processes, leads to significant losses of gold during mining and processing of ore which comes up to 25-35\%. A horizontal integration of companies into alliances can create the opportunity for accessing to more efficient technologies, by uniting the capitals, thereby strengthening this weak position and eliminating the threats.

The threat of unpredictability of gold prices and Russian currency can be mitigated by using the strength - volume of the mineral resources base. The rational usage of different kinds of gold ore from different parts of deposits at the particular time allow to the gold mining companies to mitigate the losses from the prices drop and fluctuation of Russian currency.

In surface mining of gold deposits about dozens different technological strategies for mining are being used. The techniques of some strategies can be applied in the similar conditions, however, the way of implications and economic effect will be different. In this 
regard, it's very important constantly adapt the basic strategic moves to the certain case and situation to get rationalized strategy corresponding particular working environment the company operates in.

\section{Conclusion}

Due to the shortage of gold reserves of large and medium-scale ore deposits in Russia now and in the future, the consistent expansion of the development of small-scale gold deposits has a great importance. A large number of previously identified and explored small-scale gold deposits and, first of all, close and slightly disjointed after their additional exploration, can form the significant part of the regional gold resource base and insure future gold mining development, using mainly the open pit method. Successful mining of new gold ore deposits is possible using production strategies adjustments based on maximising the mechanization, automatization and optimization as well as rationalisation of each of technological parameters.

\section{References}

1. B. Yacenko, A. Loza and others, The review on Russian gold mining 2018. (Gold mining unioon, 2019)

2. P. O’Connell, C. Alexander and others, GFMS Gold Survey 2016, (Londres: Thomson Reuters, 2018)

3. F. A. O’Connor, B. M. Lucey and D. G. Baur, Journal of International Financial Markets, Institutions and Money, 40, 186-196 (2016)

4. S. G. Kashuba. (2016). "The overall results of 2015 and the forecast of branch development till 2020. Exhibition: Mining World Russia Crocus Expo, Moscow." (Accessed 15.05.17)

5. The Central Bank of the Russian Federation, 2020 https://cbr.ru/eng/statistics/ (Accessed 10.08.2020)

6. N. C. Kuhrt, Politics, 34(2), 138-148 (2014)

7. A. Suglobov, I. Vorontsov, Accounting. Analysis. Audit, 3, 83-89, (2017)

8. G. Arhipov, Mineral resources for mining industry of the Russian Far-East: overview of the current state and perspectives for development (M: Gornaya Kniga, 2011)

9. E. Hellquist, Cambridge Review of International Affairs, 29(3), 1-25 (2016)

10. S. Bagheri and H. R. Akbarpour, Procedia Economics and Finance, 36, 89-95 (2016)

11. N. Rötzer, M.Schmidt, Resources, 7, 88 (2018)

12. F. A. Camisani-Calzolari, Journal of the Southern African Institute of Mining and Metallurgy, 104(5), 297-305 (2004).

13. S. Henley, European Geologist European Geologist, 39, 40-43 (2015) 